\title{
Chapter 6 \\ Case Des Tout-Petits: Reforming Early Childhood Education in Senegal
}

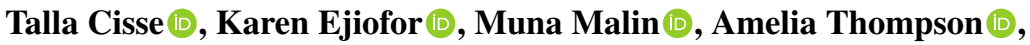 \\ and Yuan Zhao
}

\begin{abstract}
Education systems around the world are grappling with how to respond to a significant global health crisis stemming from the Covid-19 pandemic. Under the leadership of President Abdoulaye Wade, in the early 2000s, Senegal undertook a significant educational reform that sought to address disparities in academic and health challenges faced by early learners. This chapter examines Cases des Tout-Petits, a reform targeting children 0-6 years old, through the lens of Fernando Reimer's five perspectives of educational change. This chapter offers insights to policy makers, researchers, educators, and program designers around the world interested in learning from a dual reform that dramatically shifted the early childhood development landscape in Senegal.
\end{abstract}

\section{Abbreviations}
ANCTP National Agency of Cases des Tout-Petits
CTP
Case des Tout-Petits (“Children's Huts")

\author{
T. Cisse \\ Harvard Graduate School of Education, Dakar, Senegal \\ e-mail: tallacisse@gse.harvard.edu \\ K. Ejiofor \\ Harvard Kennedy School, Cambridge, USA \\ e-mail: Karen_ejiofor@hks.harvard.edu \\ M. Malin \\ Harvard Graduate School of Education, Lawrenceville, USA \\ e-mail:muna.malin@colorado.edu
}

\author{
A. Thompson ( $\varangle)$ \\ RenewToday I Harvard Graduate School of Education, Brooklyn, USA \\ e-mail: amelia@renewtoday.net \\ Y. Zhao \\ Harvard Graduate School of Education, Haidian District, Beijing, China \\ e-mail: yuanzhao@gse.harvard.edu
}




$\begin{array}{ll}\text { ECD } & \text { Early childhood development } \\ \text { JICA } & \text { Japan International Cooperation Agency } \\ \text { MDG } & \text { Millennium Development Goals } \\ \text { MFPE } & \text { Ministry of Family and Early Childhood } \\ \text { PNDIPE } & \text { National Policy for the Integrated Development of Early Childhood } \\ \text { OECD } & \text { Organization for Economic Co-operation and Development } \\ \text { PDEF } & \text { Education and Training Development Program } \\ \text { UNESCO } & \text { United Nations Educational, Scientific and Cultural Organization } \\ \text { UNDP } & \text { United Nations Development Project } \\ \text { UNICEF } & \text { United Nations Children's Fund } \\ \text { UNFPA } & \text { United Nations Population Fund } \\ \text { USAID } & \text { United States Agency for International Development }\end{array}$

\subsection{Introduction}

The current global pandemic underscores the harsh intersection of global health and education policy; decisions that are made to protect global health are inextricably and more obviously tied to how to educate a citizenry and promote effective public health. For this reason, the exploration of Senegal's early childhood education system during President Abdoulaye Wade's tenure is of relevance as it was the first national education reform policy in Senegal that was largely driven by and tied to education access and health inequities. President Wade's vision of an education system that prioritized the health of its children offers lessons and opportunities for countries around the world redesigning education through a global pandemic.

Considering mass school closures beginning in the spring of 2020 impacting more than one billion students worldwide including millions of students in Senegal, governments have been grappling with how to reopen schools with health concerns in mind, especially pre-primary and primary schools.

On March 16th, Senegal became the first country in sub-Saharan Africa to announce the closure of all schools in its efforts to fight against the spread of COVID19. This decision impacted approximately 8 million students, putting a strain on Senegal's weak healthcare and education infrastructure (UNESCO, 2021). Prior to the pandemic, Senegal's youth population was one of the world's most vulnerable due to many children disconnected from formal education. According to the Foreign Policy's COVID-19 Global Response Index, Senegal was ranked 2nd out of the 36 countries on global pandemic response despite its lack of doctors ( 7 for every 100,000 people) (Chakamba, 2020). The country is now wrestling with how to properly reopen schools while keeping health regulations at the forefront. Fortunately, the Senegalese government has experience delivering a dual-focus model that incorporates education and health.

In the early 2000s, President Wade sought reform efforts to tackle disparities in access to early childhood education and child health outcomes between rural and 
urban contexts. Towards this end, the early childhood education program, Cases des Tout-Petits (CTP), also known as "Children's Huts", was officially developed in 2006 by a decree creating the National Agency of Cases des Tout-Petits (ANCTP). President Wade aspired to build 28,000 hut-shaped structures that would become community-based spaces for learning and supportive services, including immunizations, specifically designed for rural children from birth to 6 years old (Turpin Bassama, 2010). His commitment to whole child development through advancing educational and health equity marked a progressive directional shift for education policy in Senegal. This reform inspired greater alignment between Senegal and the international community's interests in supporting early childhood development. We argue this reform is relevant because of its unique combination of education and health, which at its conception in the early 2000s, was not a global priority. As we consider designing twenty-first century education systems after a global pandemic, the findings of this research could lend itself well to existing and future early childhood development initiatives that embody a holistic approach. Furthermore, we argue this research informs a growing body of knowledge that considers the limitations of education reform through the lens of public health in sub-Saharan Africa. The ambitious nature of the reform and the subsequent challenges have demonstrated the additional capacity needed to fully implement reforms that have a dual focus.

This chapter investigates and reports the reasons that led Senegal to adopt CTP between 2000 to 2010, the motivation behind Wade's vision, an analysis of the reform through Fernando Reimers' five perspectives of educational change (Reimers, 2020), as well as its results and challenges. The analysis utilizes both quantitative and qualitative data from: (1) a review of literature, reports, and articles; and (2) interviews with Senegalese stakeholders such as the current United Nations Ambassador of Senegal, Cheikh Niang; Senegal's former Prime Minister, Dr. Aminata Touré; USAID representative and former national Education Inspector, Malick Diop; a current CTP Principal, Fanta Ndao, and a current CTP teacher, Nafi Guiro. At the inception of the reform, early childhood development was not standardized in Senegal. For this reason, this research encompasses early childhood development programming efforts that span a range of ages between 0 to 6 years old. While Senegal is currently going through a new iteration of CTP under the current administration of President Macky Sall, this work offers a critical assessment of the original model and its potential contribution in shaping early childhood education in postcolonial contexts and globally through a comparative lens.

\subsubsection{Research Limitations}

Due to a lack of adequate monitoring and evaluation from the agencies overseeing CTP, it was difficult to obtain information about academic performance as well as the long-term academic trajectory of children who have participated in CTP. Despite this limitation, we were able to collect sufficient information on other aspects of CTP through interviews with a range of stakeholders including current educators. 
This limitation was minor in relation to the insights offered through these interviews and other sources.

\subsection{Country Context Prior to the Reform}

Senegal is a low-income country in West Africa. In 2001, about 56.2\% of the population lived below \$2 USD per day (Watkins, 2006). Senegal's human development index was 0.46 in 2005, ranking 156th out of 177 countries covered by the Human Development Index report according to the UNDP (Watkins, 2006). A moderate ranking on the Gini index revealed Senegal also had a wide disparity in income distribution and consumption (Watkins, 2006).

\subsubsection{Developments in the Early Childhood Landscape}

Amidst global economic turbulence in the 1980s, Senegal experienced stagnant economic growth and setbacks in education due to a growing population. Leadership reacted with an emphasis on primary schooling resulting in the marginalization of pre-school education (Rayna, 2003). In response to the decline in pre-primary outcomes, early childhood learning became a key feature of the "Ten-Year Education and Training Plan" introduced in the late 1990s and financed by the World Bank (Rayna, 2003). The plan was designed "to break the vicious cycle of poverty" (Turpin Bassama, 2010). This plan was part of the country's Education and Training Development Program (PDEF), which created the policy framework for education in Senegal. The plan had three main objectives: (1) create an education system that will cultivate productive Senegalese citizens aiding in the development of the country; (2) teach Senegalese values so every citizen can uphold the norms and customs of the country; and (3) be free and compulsory until the age of 16 (Rayna, 2003).

In 1999, an interdisciplinary team with expertise in education, nutrition and other fields produced the Study for Early Childhood Development; the report detailed the challenges facing Senegal's young children about education, health, and nutrition (Rayna, 2003). The report also recommended the creation of physical low-cost structures that were appropriate to and could fulfill a range of community needs (Rayna, 2003).

The election of President Wade marked a historic shift in the education trajectory of Senegal. In 2000, President Wade was determined to address the growing gaps in early childhood education by making it a top priority in his presidency (Toure, personal communication, 2020). In particular, he desired to offer support to children facing greater threats to social vulnerability and marginalization, such as those living in rural contexts and other areas lacking access to kindergarten and nursery school programming (Taniguchi, 2014). During that year, Senegal prioritized early childhood development as an outcome of the Declaration of the World Education Forum 
organized in Dakar by international organizations including UNESCO, UNICEF, UNDP, UNFPA and the World Bank (Taniguchi, 2014). The "Dakar Framework for Action" was developed to improve access to education, the quality of education and the management of the education system (Taniguchi, 2014).

\subsubsection{Inequities in Early Education \& Health}

In 2000, children aged 0-8 years old represented $26.2 \%$ of the total population in Senegal (Turpin Bassama, 2010). Senegalese children faced tremendous educational challenges. Pre-primary school enrollment was less than $2.5 \%$ of children of the appropriate age at the start of President Wade's tenure in 2000 (World Bank, 2006). The World Bank reported disparities among rural and urban children and lower literacy rates than other countries in sub-Saharan Africa that posed persistent challenges to achieving educational equity and Millennium Development Goals (MDG) (World Bank, 2006). The enrollment rate was $4.3 \%$ in urban areas as compared to $0.3 \%$ in rural areas. Low quality and inequitable service delivery left youth lacking in opportunity and essential life skills (USAID, 2019). Under these circumstances, the government aimed to promote early childhood education, which could prepare children for future learning to reduce failure rates in later stages of education. Senegal aspired to raise the pre-school attendance rate to $30 \%$ and improve the quality of early childhood services by 2010 (Rayna, 2003).

The health outcomes among young children were also dire. In 2005, the underfive mortality rate was 119 per 1,000 , and the rate of measle immunization was under 54\% (UNICEF, 2013). The percentage of malnourished children (22.7\% for children under 5 years old) was lower than the average for sub-Saharan Africa at 29.6\% (Humblet et al., 2009). Disparities separating children in rural communities and cities were also a growing concern. For example, whereas approximately $80 \%$ of the urban population lived within 30 minutes of a health facility, only $42 \%$ of rural residents had similar access resulting in lower immunization rates and higher rates of infant mortality. Further, although under 5 and infant mortality rates were declining at an annual rate of $1.1 \%$ and $1.4 \%$ respectively (World Bank, 2006), these declines were significantly less than the $4.4 \%$ annual decline projected to help Senegal achieve the MDG (World Bank, 2006). CTP emerged from this context.

\subsection{The REFORM: Cases Des Tout-Petits}

Cases des Tout-Petits (CTP), also known as "Children's Huts," served children ages 0-6 years old from rural backgrounds and provided a space for learning and receiving supportive services (Turpin Bassama, 2010). 


\subsubsection{Symbolism and Value of the Huts}

Huts were selected as the focal physical structure embodying the reform and are integral to understanding the symbolic, cultural and community-based aspects of the reform. These hexagon-shaped buildings had several rooms specially designed for different subjects of learning such as alphabets, literature, and mathematics (Diop, personal communication, 2020). The hut also contained a kitchen, infirmary, an office for supervisory staff, toilets, a food storage store and a landscaped courtyard for games and outdoor activities (e.g., small animal farm-raising and gardening) (Turpin Bassama, 2010). All huts were built from exported materials of high quality (Diop, personal communication, 2020). The shape and materials of the huts symbolized ancestral civilization and attachment to African values (Turpin Bassama, 2010). The costs associated with the building of one hut were considerable and estimated at 18,200,000 CFA (approx. \$27,000 USD), ${ }^{1}$ due to the imported building materials (Rayna, 2003). State governments were expected to construct the buildings while the local communities managed them. The architectural model was created by Archi-Art, and the architecture of a second generation of the huts was improved with support from the Japan International Cooperation Agency (JICA), Japan's international development agency (Diop, personal communication, 2020; Turpin Bassama, 2010).

\subsubsection{Theory of Action}

CTP's theory of action was as follows: If Senegal invests early in children's development, communities and cultural awareness, then children will be able to contribute positively to the Senegalese economy in the future. Further, the Ministry of Family and Early Childhood (MFPE) stated, "The State has chosen to invest in child capital to ensure its succession. Early childhood development in Senegal is not a social action, but a macroeconomic action which is at the heart of development through the enhancement of human resources" (Turpin Bassama, 2010).

\subsubsection{Program Elements}

\section{Element 1: Supporting Holistic Development of Children}

The CTP reform offered an integrated three-pronged service delivery model comprised of health, nutrition and education (World Bank, 2018):

\footnotetext{
${ }^{1}$ All conversions of Senegalese CFA Franc into USD are based on 2002 conversion rates from World Bank, 2016.
} 
(1) Health: Screening for health deficiencies and disorders in children, providing immunization, and giving hygiene education for children and parents

(2) Nutrition: Offering children balanced meals and educating parents about nutrition

(3) Education: Preparing children for primary school through activities centered on literacy, math, exposure to technology and building morality and cultural values by enlisting community members to support instruction.

\section{Element 2: Mobilizing and Involving Children's Community}

Community is at the heart of the CTP model. CTP was managed and supervised by self-elected regional bodies called preschool committees to ensure efficient operations on the local level (Humblet et al., 2009; Diop, personal communication, 2020). The local committee oversaw selecting key personnel and a formal principal was responsible for managing schools and hiring teachers (Diop, personal communication, 2020). The core actors of CTP included: (1) a "monitor" who has obtained a baccalaureate degree served as a multipurpose facilitator; (2) "assistant mothers" literate in the local language participated in the running of activities and supported facility cleanliness and distribution of meals; (3) grandparents as morality educators; (4) Quranic teachers responsible for religious instruction and (5) health workers who conducted immunizations for children (Rayna, 2003; Turpin Bassama, 2010). The role of family members as educators demonstrated the participation of the local community in supporting the whole development of children.

In addition, although the salaries of the employees, upkeep and management of the huts were funded by the state government (Turpin Bassama, 2010), the community was expected to make financial contributions, albeit symbolic, to maintain the service of CTP. Auxiliary staff was paid for by the community (Rayna, 2003). The purpose of community participation was to avoid overreliance on government support by conveying to the community that their active involvement was crucial to children's prosperity. This model took advantage of existing systems that already influenced children's development to meet community needs and to reduce operational costs.

\section{Element 3: Incorporating Cultural Awareness}

Cultural and moral education were key components of CTP. It enlisted parents and grandparents to teach local customs and to provide children with a foundation that rooted them in Senegalese values. Instruction in the local language was central to the transmission of cultural and moral education. Senegal is home to many local languages including Wolof, Pulaar, and Sereer. However, due to the influence of French colonization from 1895 to 1960 , French is the official language of instruction in the school system, which has caused a gap between children's language of instruction at home and school. Quranic teachers were integrated into the educational model, which merged traditional religious education and formal preschool education. The inclusion of these non-traditional teachers reflected the commitment to make CTP culturally relevant. These actions built a connection between local cultural values and broader knowledge about child development (Soudee, 2009). This culturally 
responsive approach relayed to children that their ethnic and religious background were important for their development and demonstrated reverence to the national identity of Senegal.

\subsubsection{Key Milestones in the Design and Implementation of CTP}

In 2001, the oversight of CTP was transitioned to an autonomous ministry, MFPE and finally to the National Agency of Cases des Tout-Petits (ANCTP) (Turpin Bassama, 2010). In 2004, a meeting concerning CTP was held in Dakar. The participants included President Wade, his advisors, members of the Ministry of Family and Early Childhood (MFPE), the Ministry of Education, and the Ministry of Agriculture and Rural Equipment. The meeting covered core issues such as the model design, financial supply, and the management of CTP (Diop, personal communication, 2020). In 2006, a new "National Policy for the Integrated Development of Early Childhood (PNDIPE)" was adopted (Turpin Bassama, 2010). The implementation of this policy marked the start of the CTP program piloted by ANCTP. Until 2007, a total of 180 huts were built and operational throughout the country, and 106 of them were in rural areas (Turpin Bassama, 2010). Circa 2009, the construction of new CTPs gradually came to a halt due to the high cost of the construction materials (Diop, personal communication, 2020).

\subsection{Implementation Analysis}

This section analyzes the implementation and identifies strengths and weaknesses of CTP through the lens of Fernando Reimers' five perspectives: cultural, psychological, institutional, political, and professional.

\subsubsection{Cultural Perspective}

Approaching education through a cultural perspective entails aligning educational goals with societal needs; more specifically, the cultural perspective considers the societal expectations of education (Reimers, 2020). In the early years, Senegalese parents expect children to be immersed in learning customs and to begin Quranic study as a way of attaining cultural and religious knowledge. It is common for children to attend Quranic schools before attending primary school. One of the strengths of CTP that reflects a cultural perspective is that it mirrored broader Senegalese expectations and heavily emphasized Senegalese values. Another strength is CTP's 
incorporation of Quranic instruction which demonstrated the high regard of religious education of children in Senegal. President Wade wanted the huts to represent the home life of children. In the classroom, children sat on the floor, sang Senegalese children's songs and played traditional games (Rayna, 2003). The instatement of grandparents as key educators and conveyors of cultural values also displayed a commitment to the traditional knowledge transfer between elders and children. In contrast, CTP was also developed to shift health and hygiene practices; at the time, handwashing was not a common practice which contributed to the spread of disease.

CTP challenged the expectation that the government would be responsible for paying for educational services by expecting financial support from communities to build ownership of the model. Despite the strength of this community-ownership approach, this expectation was not sustainable considering the lower socioeconomic levels of most communities.

\subsubsection{Psychological Perspective}

Employing a psychological perspective in education considers the science of how students learn (Reimers, 2020). The rising population of children in the context of inadequate health services coupled with malnutrition contributed to deleterious living conditions for Senegalese children, especially in rural areas (Rayna, 2003). Undeniably, students learn best when they are healthy and well-nourished. This understanding undergirded the creation of CTP. It strived to provide meals to students to support their capacity to learn and focus on school (Niang, personal communication, 2020). The wellbeing of children was supported by maintaining an infirmary in each hut which administered health checkups and encouraged healthy habits, such as hand washing, to reduce the spread of disease (Taniguchi, 2014).

Additionally, CTP embodied the psychological approach necessary to ensure children can thrive at school. Attention was paid to what students learn and instruction was designed to be age appropriate. Classroom activities were play-based and included toys and Senegalese games (Rayna, 2003). Equally important, students learn best in a language that is familiar to them. Research shows that mother tongue instruction in sub-Saharan African schools is "the most efficient in imparting human capital," which lends itself well to the socio-economic goal of CTP's theory of action (Ramachandran, 2017). This corroborates the language design of CTP. Moreover, the assistant mothers, literate in the children's native language, were selected as an important actor of CTP. Although CTP adopted the unified national preschool curriculum, the home-like environment, specially designed learning spaces, and culturally sensitive multi-educator model of CTP offered students a favorable learning environment. Given the strength of the psychological perspective of some rural municipalities, children from CTP showed better performance in primary school preparedness than those attending traditional preschool (Diop, personal communication, 2020). 


\subsubsection{Institutional Perspective}

An institutional perspective requires identifying the norms, structures, organizations, and elements of the system that can enhance education (Reimers, 2020). This perspective is essential in developing an efficient program. Mapping out existing institutions was one of the preliminary steps of Wade's administration. Some of the roles of Ministry of Family and Early Childhood (MFPE), regarding CTP, was to identify appropriate hut sites considering the established criteria (i.e., adequate water supply and location), find and train qualified staff, decide on the equipment required to build, and mobilize the community (Rayna, 2003). The role of managing CTP was later transferred from MFPE to the National Agency of Cases des Tout-Petits (ANCTP).

The stakeholders included the education and training inspectors, health organizations, nongovernmental organizations, the Nutrition Coordination Unit of the Government of Senegal, the Ministry of Education, and the Ministry of Health and Social Action (Diop, personal communication, 2020). Additional stakeholders involved were the Ministries of Environment and Public Hygiene, Health and Disease Prevention, Justice, and Culture and Communication (Rayna, 2003). The construction and funding of huts also engaged NGOs, governmental departments and corporations.

On the ground level, CTP depended on the participation of members of rural communities to function efficiently. CTP also relied on the effective coordination and delegation of tasks between the national, regional, and local authorities with an emphasis on community ownership. This structure was meant to support the sustainability of the model in shaping the delivery of early childhood services beyond a single presidential administration.

The commitment to coordinate a range of key stakeholders from education, health and civil society demonstrates a strength of the adaptation of the institutional perspective to CTP. Designing holistic programming with a dual focus for early learners necessitates such an approach. However, further analysis suggests this perspective was challenged by capacity limits. These limits constrained the likelihood of clear and efficient communication and participation among all stakeholders, the organization of clear and data-driven education and health metrics to support analysis, and the means to ensure all parties effectively implemented the reform. Therefore, the weaknesses in CTP's institutional perspective challenged the reform's overall and long-term success.

\subsubsection{Political Perspective}

The political perspective, as described by Reimers (2020), illustrates how various groups' interests must be addressed and considered during the design and implementation of a reform. Arguments have been made of the political forces that are powerful 
in shaping educational reforms and practice. As Reimers (2020) noted, political interests can often override the educational interests of students and parents. Political interests influenced the adoption of CTP. In April of 2000, through the World Forum on Education and the adoption of the Millennium Goals (MDGs), President Wade laid out an ambitious vision to improve early childhood outcomes. Implementation of that vision started with the launch of CTP.

Prior to this point, early childhood education was not a presidential priority. Thus, CTP became a politicized reform because of its association with President Wade. Even though the various departments involved in the reform established and shared similar goals, President Wade's control of the effort created barriers among the parties including education and health officials (UNESCO, 2006). For example, the ANCTP, created to manage the reform, was directly overseen by President Wade rather than one of the ministries. Ultimately, due to the politicized nature and visibility of the reform, urban and rural leaders faced pressure to adopt CTP models in their contexts (Diop, personal communication, 2020). Thus, the political pressure resulted in a shift from CTP's design to focus on rural areas. Along with local support, the Japan International Cooperation Agency (JICA), which had a history of working with communities throughout sub-Saharan Africa, was instrumental in providing financial and technical support to building huts in rural towns and villages in Senegal.

The active participation of diverse stakeholders highlights Reimers' (2020) definition of "consensus-building that influences a number of national specialists and community leaders that are in charge of implementing the policy." Lastly, due to the political realities and President Wade's fervor in adopting CTP, the planning committee failed to establish a financial plan, a discrete list of policy indicators for education and health outcomes, and a plan of action, the last two of which were prepared but not officially adopted (UNESCO, 2006). Thus, while the government adopted CTP in 2004, the Ministry of Education asserted in 2006 that the policy was yet to be "validated" (UNESCO, 2006) revealing that there were lingering disagreements about specific policy elements.

More recently, CTP remains one of the main vehicles for which early childhood health and academic services are delivered nationally. However, a primary challenge early childhood services face is prioritizing quality dual service delivery while effectively navigating political interests and coordinating across various entities mostly within the public sector, but also in the private sector (World Bank, 2017).

\subsubsection{Professional Perspective}

The professional perspective assesses the level of professionalization of teachers and other educators responsible for instruction and in the case of CTP, the delivery of health services. It also underscores the capacities and knowledge of educators (Reimers, 2020). Clarence Beeby, who led reforms to advance education equality in New Zealand argued that educational systems are characterized by the level of skill and professionalization of its teachers (Reimers, 2020). Senegal's well-intentioned, 
community-centered model attempted to prioritize teacher capacity and development, but there were insufficient support and results. While children were provided with a care-orientated model, they were often served by teachers with low education levels compared to higher income countries (UNESCO, 2017). It is generally understood that teacher quality is the greatest determinant of student achievement. Although there is a lack of CTP student outcome data, student achievement may have been negatively impacted by receiving instruction from monitors with low education levels. CTP educators were provided with government-led training. The ANCTP also provided facilitators, who served as monitor trainers, with two-month training experiences focusing on the objectives of the National Policy for Integrated Childhood Development (Rayna, 2003). This training was augmented by an additional six-month course in teacher training schools which elevated the professional status of these staff (Rayna, 2003). Other volunteer staff, such as assistant mothers, were literate in the local language and were expected to complete at least primary school education. These community members were required to participate in two weeks' initial training with inspectors and nutritionists to work in CTP (Rayna, 2003).

Pre-school education inspectors had a higher level of training and were appointed coordinators of the regional branches of the ANCTP. They supervised and trained personnel, as well as monitored and supervised CTP management committees. At the departmental level, the coordinators were supported by teachers called "focal points." Although progress was made in the professionalization of the teacher workforce, such as strengthening links across teacher settings to promote continuity in learning and focusing broadly on children's holistic development and well-being, additional strides were needed to strengthen the workforce. Current iterations of the model have improved regarding the professional perspective; the state now hires, trains and deploys teachers to CTPs around the country (Ndao, personal communication, 2020).

Regarding health, USAID (2013) has found in three sub-Saharan African countries, "offering nutritional education programs for women, particularly those with low levels of education, would help them attain better nutritional outcomes for their children." CTP was designed to encourage assistant mothers and grandparents to support academic learning and to be involved in operational activities including meal preparation. However, a specific focus on educating caregivers on child nutrition may have benefited children's long term health outcomes. While CTP has taken great strides in staffing huts with caring community members, increasing the professionalization of teachers with ongoing and standardized training and providing nutrition education to caregivers could lead to an improved social status of the profession and greater health and academic outcomes for children.

\subsection{Results}

Results of the reform can be grouped under three main categories: (1) academic enrollment and access; (2) child health improvements; and (3) community development and the social value of the child. 


\subsubsection{Academic Enrollment and Access}

Access to equitable early childhood education in rural settings was a major facet of the reform. Enrollment in CTPs grew gradually during the reform period with a high pre-enrollment of girls who made up about $52 \%$ of preschool children (Diop, personal communication, 2020). CTP helped contribute to increased enrollment rates in pre-school education from 3\% in 1999 to $13 \%$ in 2010 (Taniguchi, 2014).

Despite this improvement, pre-school education was still underutilized in rural areas (Taniguchi, 2014). By 2009, there were at least one early childhood development education option per 1,000 for 3-6-year-olds (UNESCO, 2010). However, service density was not equally distributed. In fact, in two primary areas, this density was doubled, Dakar and Ziguinchor, a southern region that at that time was reported to have the highest education rate (UNESCO, 2010). A UNESCO report highlighted the degree of inequity between early childhood institutions in rural and urban districts: the inequality indicator between regions is a ratio of the densest (Dakar where there were 2.4 options per 1,000 children) and least dense access options (Kaolack where there were 0.26 options per 1,000 children) (2010). Children in Kaolack were 9 times less likely to have access to early childhood development programming than children in urban settings (UNESCO, 2010). Although two-thirds of preschool-age children lived in rural areas, only $38 \%$ of early childhood institutions were found in these areas, while $62 \%$ were in urban contexts (UNESCO, 2010). CTP contributed to the overall access and availability of early childhood services throughout Senegal. However, these findings suggest there should be an analysis of the services needed to determine service density rather than decision-making based on political and/or public pressure.

\subsubsection{Child Health Improvements}

In 1999, a report described malnutrition as a significant public health problem attributed to $30 \%$ of all pediatric hospitalizations; additionally, chronic malnutrition was estimated at 19\% (Rayna, 2003). Child mortality was shown as higher in rural areas and associated with mother's educational levels (Rayna, 2003). Child mortality rates were reported to have been 70 per 1,000 for the $0-1$ age group, 81 per 1,000 for the 1-4 age group and 145 per 1,000 for the 4-15 age group (Rayna, 2003).

Against this backdrop, CTP helped to encourage improvements in health outcomes for children. UNICEF reported the underweight prevalence in children under 5 years old from 2008-2012 in urban areas was $11.8 \%$ compared to rural areas where the ratio was $21.3 \%$ (UNICEF, 2013). This finding suggested that a child in a rural setting was two times more likely to be underweight than in an urban setting (UNICEF, 2013). However, nationally mortality rates for children under the age of five continued to fall from approximately 118 per 1,000 children in 2000 to 75 per 1,000 children in 
2010 (UNICEF, 2013). The provision of meals and immunizations as part of the CTP model affirmed these commitments. These measures help demonstrate how providing health services was a key pillar in supporting the holistic development of children even if disparities persisted between rural and urban areas.

\subsubsection{Community Development and Social Value of the Child}

Community development may be understood across two primary areas for CTP: structural development and human capital development. During President Wade's tenure, approximately 599 huts were created (Diop personal communication, 2020). UNESCO reported $37 \%$ of huts were fully equipped with multimedia equipment and games, while $97 \%$ had libraries. Additionally, in 2007, $36 \%$ of the 338 huts built and/or were in development were fully equipped to support outdoor play and $79 \%$ with indoor equipment (UNESCO, 2010). However, 599 huts were far lower than the president's initial vision of 28,000 huts. The ambitious nature of the reform coupled with the costs of each hut and challenges related to coordination impeded progress toward this goal.

Research suggests the CTP approach made best use of local human resources through in-community recruitment of staff for children's huts (Rayna, 2003). The integration of grandparents as support personnel alongside trained teachers encouraged the community-ownership design of this model. Additional use of local assets included the use of traditional games and local languages as well as "oral, written and religious traditions" (Rayna, 2003). A focus on whole child development became a national interest with the emergence of CTP. This reform helped Senegal embrace international standards related to child development and labor that protect the rights of children (Diop, personal communication, 2020). As a national Senegalese education inspector, who is now a USAID representative remarked, CTP helped society value children and provided practical support for mothers to help infants and toddlers overcome health and nutritional barriers to development (Diop, personal communication, 2020).

\subsection{Challenges}

Key challenges of the reform relate to (1) professional development and curriculum; (2) cost structure; (3) student achievement data; (4) coordination and (5) the studentteacher ratio. 


\subsubsection{Professional Development and Curriculum}

In terms of health, the design of CTP necessitates staff who are multiskilled in identifying and treating a range of health deficiencies in children and who have been provided with the capacity to train mothers, grandparents and other community members supporting academic learning (Rayna, 2003). In educational terms, CTP encourages a range of skill sets among staff including - "creativity, socialization, openness to technology" (Rayna, 2003). This approach must therefore be reflected in staff, the curriculum used to guide instruction and professional development programming and resources. Though aspects of supporting early childhood development were included in training offered to staff, a need for training and curriculum that met each facet of CTP would support implementation with a higher degree of fidelity to the model's intentions. Dual capacity development is needed for each component of implementation including staffing, curriculum, training, monitoring, and programming.

\subsubsection{Cost Structure}

The cost structure of CTPs needed a more robust financial model to support its sustainability. It may reflect an over prioritization on the physical huts to the detriment of other key facets of an effective education reform such as staff training and development. In addition to 18,200,000 CFA (approx. \$27,000 USD) for the building of a hut, 4,060,000 CFA (approx. \$6,000 USD in 2002) was devoted to equipment, 1,648,000 CFA (approx. \$2,500 USD) for staff, 500,000 CFA (approx. \$750 USD) for training, 1,000,000 CFA (approx. \$1,500 USD) for monitoring and evaluation (Rayna, 2003). Additionally, Senegal required financial support from international bodies including JICA (Diop, personal communication, 2020). Although the state was responsible for constructing huts, local communities and parents were responsible for a range of costs including school supplies and meals (which are currently 2,000 CFA (approx. \$3 USD) per month for parents) (Ndao, personal communication, 2020). However, many families lack the financial means to adequately support the operations of local educational structures. Recent budget cuts have resulted in reduced hours for key staff including teachers, custodians and cooks (Ndao, personal communication, 2020). Therefore, model fidelity has been challenged. Over time, reductions in funding resulted in limited and insufficient resources for appropriate monitoring and evaluation programming to assess the effectiveness of the reform and its projected impact on future generations of Senegalese children. 


\subsubsection{Student Achievement Data}

There are limited data monitoring, evaluation, and performance management structures in Senegal. While anecdotal evidence may suggest there were positive impacts of CTP on children in rural communities (Diop personal communication, 2020), more robust structures are needed for empirical analysis and adequate evaluation. The primary goals of CTP were to reduce inequities in early childhood access and health between rural and urban communities. For this reason, data that helps compare enrollment, mortality and immunization rates among 0-6-year-olds help assess how CTP functioned to move Senegal toward greater equity in these areas. However, student level achievement data is needed in considering the efficacy of CTP as an education reform. Limitations in funding and coordination precluded the likelihood of collecting student level data and the potential for longitudinal study of the reform. This data could be useful in evaluating how effectively CTP has helped prepare Senegalese early learners for matriculation in upper grades and successfully enter and contribute to the labor market (Rayna, 2003).

\subsubsection{Coordination}

Historically the scope of early childhood learning in Senegal has been fragmented. Yet, the successful adoption of the CTP model required a highly cohesive coordination among various stakeholders. A more systematic and ongoing review of all the functions of the various stakeholders and an accurate assessment of the human resources needed to effectively implement the work alongside a technical coordination mechanism would have benefitted implementation (Rayna, 2003). Additionally, each fractal of the coordination and technical arms could have included decisionmaking representatives from education, health and nutrition departments (Rayna, 2003).

Further, the multi-pronged model, though overseen by a separate government agency, lacked sufficient cross-agency coordination to support effective implementation. Early meetings of key staff were reported to consist of the three department heads and the head of the ministry but was inadequate in interconnecting the various projects while other staff seemed poorly acquainted with key aspects of the work (Rayna, 2003). Therefore, the creation of multi-sector committees at the national and decentralized levels may have helped implement the model more effectively (Rayna, 2003). Among the various bodies involved in the reform, there was confusion within the administration of what responsibilities were associated with which key structural factors. 


\subsubsection{Student-Teacher Ratio}

Despite efforts by the government to improve CTP, the education services were viewed as poor in quality and exacerbated by high student-teacher ratios (Rayna, 2003). It was noted the student-teacher ratio "was higher in 2005 than in 2000 and dropped again in 2008, with 27 students per section for all sectors for 3-6year-olds" (UNESCO, 2010). In the region of Matam, the average ratio was much higher, although it was the region with the lowest density of services in Senegal (UNESCO, 2010). Similar observations were noted for other rural regions where student-teacher ratios were consistently higher. Additionally, there were instances of higher student-teacher ratios in every region when compared to the average ratio for that area. Currently, the student-teacher ratio of CTP (45:1) is still significantly higher than the international standard of 14:1 (UNESCO, 2017).

\subsection{A Path Forward}

Following the global economic crisis of the 1980s, Abdoulaye Wade, then President of the Republic of Senegal, stood on the stage of the Forum for Education for All to roll out an audacious vision to transform his country's education system. Rooted in Nyerere's belief that "most of Africa's education systems are based on the assumptions of a colonialist and capitalist society, and therefore designed to transmit the values of the colonizing power and to train individuals for the service of the colonial state" (Nyerere, 1968), President Wade offered a bold path forward to depart from the French colonial school system and improve education for Senegal's children.

In analyzing his hopes to address the disparities in early academic achievement and health inequities between rural and urban contexts through the framework of the five perspectives, the reform demonstrates mixed results. In the education realm, Senegal has generated improvements in preparing early learners to succeed in subsequent years by focusing on literacy, math, and early knowledge of technological skills. A critical component of the reform was to advance a system that supported the development of the community and broader society in which all members share, not only resources, but the responsibility to educate its future leaders. This is evident in the reform's focus on native tongues as the language of instruction. It also shows up in the structure of the huts which were constructed with Senegal's ancestral civilization and values in mind. Most notably, it is seen in the collaboration of parents, grandparents, health workers, and teachers to deliver a culturally relevant framework. The emphasis on serving balanced meals, providing hygiene education, and giving health screenings, can provide an important case study as sub-Saharan African countries look to model new systems post the COVID-19 pandemic. While CTP had some successes, there are concerns for future iterations. Wade's top-down approach to the reform fostered a unique political environment that was further hampered by a lack of coordination among ministries and regional authorities. A key takeaway is a focus 
on a shared implementation strategy amongst policy makers and key stakeholders during the policy formulation process.

Today, the current administration led by President Macky Sall should continue to improve the vision set by Wade in 2000. The physical structures (huts) developed during President Wade's tenure continue to exist and are used as multipurpose spaces for the community where academic programming takes place. Most importantly, it should strive to come up with a clear vision for an early education policy that places emphasis on the professionalization of teachers. There is an urgent need to provide educators with the ongoing training and support that emphasizes the mastery of literacy and math skills. It is imperative to combine the support for teachers and principals with a robust data and evaluation system that will inform future policy development and program design. Lastly, unaided by a strong national presence, Case des Tout-Petits stands to lose ground in the coming years. Thus, a clearer structure of key stakeholders and their roles could establish more fidelity for Case des Tout-Petits' longevity.

\section{References}

Chakamba, R. (2020, October 8). How Senegal has set the standard on COVID-19. Devex.https:// www.devex.com/news/sponsored/how-senegal-has-set-the-standard-on-covid-19-98266.

Diop, M. (2020, November 17). Group interview.

Humblet, C. P., Carrón, G., \& Bassama, S. (2009). Rapport de revue de la Politique d'Education et de Protection de la Petite Enfance au Sénégal. Undefined. https://www.semanticscholar.org/ paper/Rapport-de-revue-de-la-Politique-d\%E2\%80\%99Education-et-de-Humblet-Carr\%C3\% B3n/c9b1e55ab3a96e79459bb6aa90da89919ca5f222\#paper-header.

Niang, C. (2020, October 28). Group interview.

Ndao, N. (2020, December 1). Personal interview.

Nyerere, J. K. (1968). 'Education for Self-Reliance'. Freedom and Socialism. Dar ES Salaam, Oxford University Press. http://www.ibe.unesco.org/sites/default/files/nyereree.pdf.

Ramachandran, R. (2017). Medium of instruction policies and efficacy of educational. Systems in sub-Saharan Africa (p. 34). UNESCO. Retrieved October 14, 2020, from https://unesdoc.unesco. org/ark:/48223/pf0000259578.

Rayna, S. (2003). Implementation of the integrated early childhood policy in Senegal. 32. Retrieved from: http://www.worldfamilyorganization.org/wfs/Summit/wfs2007/BackgroundPa pers/ImplementationinSenegal.pdf.

Reimers, F. (2020). Thinking multidimensionally about ambitious educational. Changes in audacious education purposes (p. 10). Springer US. https://library.oapen.org/viewer/web/viewer. html?file=/bitstream/handle/20.500.12657/37709/2020_Book_AudaciousEducationPurposes. pdf? sequence $=1 \&$ is Allowed.

Soudee, A. (2009). Incorporating indigenous knowledge and practice into ECCE: A comparison of programs in the Gambia, Mali and Senegal (Vol. 11, pp. 15-23). https://www.tc.columbia.edu/ cice/pdf/25624_11_Soudeekin.pdf.

Taniguchi, R. (2014). Pre-School education in Senegal. https://www.childresearch.net/projects/ ecec/2014_02.html.

Toure, A. (2020, October 8). Group interview.

Turpin Bassama, S. (2010). La case des tout-petits au Sénégal. Revue International. D'éducation De Sèvres, 53, 65-75. https://doi.org/10.4000/ries.903 
UNICEF. (2013). Statistics: Senegal overview. https://www.unicef.org/infobycountry/senegal_stat istics.html.

UNESCO International Bureau of Education. (2006). UNESDOC. Retrieved from. Senegal Early Childhood Care and Education (ECCE) programmes: https://unesdoc.unesco.org/ark:/48223/pf0 000148045.

UNESCO Office Dakar and Regional Bureau for Education in Africa. (2010). Early. Childhood care and education, regional report: Africa. https://unesdoc.unesco.org/ark:/48223/pf0000189420.

UNESCO. (2017). Innovation and reform to improve basic education quality in. Senegal-UNESCO Digital Library. (n.d.). https://unesdoc.unesco.org/ark:/48223/pf0000146678.

UNESCO. (2021). Senegal. http://uis.unesco.org/en/country/sn.

USAID. (2013). The impact of maternal education on child nutrition: Evidence from Malawi, Tanzania, and Zimbabwe. https://dhsprogram.com/pubs/pdf/WP84/WP84.pdf.

USAID. (2019). improving education opportunities. Retrieved from USAID: https://www.usaid. gov/sites/default/files/documents/1860/Improving_Education_Opportunities_USAID_Senegal_ Fact_Sheet_Feb_2019_final_508.pdf.

Watkins, K. (2006). Rapport mondial sur le développement humain 2006. Retrieved. from Programme des Nations Unies pour le développement (PNUD): http://hdr.undp.org/sites/default/ files/hdr_2006_fr_complet.pdf.

World Bank. (2006). Independent evaluation report. Senegal country assistance. Evaluation. http:// ieg.worldbank.org/sites/default/files/Data/reports/senegal_cae.pdf.

World Bank. (2016). A decade of world bank support to Senegal's nutrition program. http:// documents1.worldbank.org/curated/en/281111484163839170/pdf/110290-PPAR-P070541-P09 7181-P115938-PUBLIC.pdf.

World Bank. (2017). Improving the early years in Senegal. http://documents1.worldbank.org/cur ated/en/551441520368304691/pdf/Concept-Project-Information-Document-Integrated-Safegu ards-Data-Sheet.pdf.

World Bank Group. (2018). Systematic country diagnostic of Senegal. World Bank, Dakar. https:// doi.org/10.1596/30852

Talla Cisse is a teacher, scholar and advocate. He works to promote educational equity by providing research and training to communities throughout the U.S. and West Africa. He is particularly interested in second language acquisition, qualitative research models, and program evaluation.

Karen Ejiofor works on the Technology and Public Purpose Project at Harvard Kennedy School, where she works on making sure emerging technologies are developed and managed in ways that serve the overall public good. Karen is pursuing a master's degree in International Education Policy at the Harvard Graduate School of Education (HGSE). Her focus at HGSE is on 21st century global competencies, digital literacy and future of work in Sub-Saharan Africa.

Muna Malin is an educator whose background is in early childhood and girls' education. Previously, she has worked in Saudi Arabia and as a Fulbright award recipient in Senegal. Muna has also advocated for early childhood education and mother tongue instruction to ministries of education. Her interests include culturally sustainable education policies and systems. She holds a graduate degree in International Education Policy from the Harvard Graduate School of Education.

Amelia E. Thompson is a consultant and the Founder and President of the social impact organization, Renew Today. She provides strategy, fundraising, monitoring and evaluation, program 
design, project management and leadership development support to social entrepreneurs, faithbased leaders, businesses and nonprofit organizations. Her passion is to design and support initiatives that expand access to education for children in vulnerable contexts around the world. She completed graduate studies at the Harvard Graduate School of Education in International Education Policy.

Yuan Zhao has recently completed her master's study on International Education Policy at Harvard School of Education. Her academic interests are in early childhood education policy and family rearing practices in East Asia. Prior to HGSE, Yuan had teaching experiences in Thailand, China, and the US. She had also worked in different fields including NGOs, ed-tech enterprises, and media.

Open Access This chapter is licensed under the terms of the Creative Commons Attribution 4.0 International License (http://creativecommons.org/licenses/by/4.0/), which permits use, sharing, adaptation, distribution and reproduction in any medium or format, as long as you give appropriate credit to the original author(s) and the source, provide a link to the Creative Commons license and indicate if changes were made.

The images or other third party material in this chapter are included in the chapter's Creative Commons license, unless indicated otherwise in a credit line to the material. If material is not included in the chapter's Creative Commons license and your intended use is not permitted by statutory regulation or exceeds the permitted use, you will need to obtain permission directly from the copyright holder. 